\title{
Addressing complex social problems with a multi-environmental stakeholder coalition
}

\author{
Walter Wymer ${ }^{1}$ (D)
}

Received: 12 July 2020 / Accepted: 2 February 2021 / Published online: 16 February 2021

(C) The Author(s), under exclusive licence to Springer-Verlag GmbH, DE part of Springer Nature 2021

\begin{abstract}
Individuals exist within an environmental context that strongly influences their overall health and welfare. Environmental context refers to the context in which a person lives, works, and socializes. This paper presents a social marketing strategic planning model which begins by analyzing the micro, meso, and macro environments to identify causes or influences of a target social issue or problem. Contributors to the social problem are prioritized with respect to the degree to which they exert influence or causality. Next, stakeholders (those who have some interest in the social problem) are identified. Stakeholder perceptions and values are examined in order to develop an effective coalition of stakeholders who can work collaboratively at the various environmental levels to ameliorate the target social problem. As social marketing has evolved in order to develop more effective solutions to complex social problems, integrating a systems approach is useful to understand the dynamics influencing the social problem. Individuals are not targeted myopically but placed into an environmental context to understand and respond to influences on unhealthy behaviors and living conditions. Engaging a coalition of stakeholders who are motivated to alleviate the causes of the social problem must be skillfully managed by social marketers but offers promise in addressing complex social problems.
\end{abstract}

Keywords Social marketing $\cdot$ Systems $\cdot$ Upstream · Downstream · macro-social marketing

\section{Introduction}

Some marketing scholars have sought to use the marketing discipline not for commercial purposes, but for prosocial purposes. Social marketers seek to address important social issues or social problems. The UK's National Social Marketing Centre (online at thensmc.com) list some social marketing problems of interest to social marketers that

Walter Wymer

walter.wymer@uleth.ca

1 University of Lethbridge, Lethbridge, Alberta, Canada 
includes child car seat usage, water rationing, and lung disease strategy. Other target social problems include public health issues like condom use, tobacco use, alcohol abuse, and vaccination availability and compliance. Social problems range in scope, scale, and complexity.

The seminal article by Kotler and Zaltman (1971) was a harbinger in broadening the scope of marketing beyond furthering commercial sales and patronage. Noncommercial marketing scholarship was viewed as "borrowing" commercial marketing concepts and applying them in another setting. Thus, the marketing scholarly community increased its acceptance of non-traditional, non-commercial marketing sub-fields, like nonprofit and social marketing.

Marketing scholars interested in discovering knowledge for the social good found that commercial marketing concepts are not universally applicable in other contexts (Gordon 2011). Bloom and Novelli (1981) describe several areas in which commercial marketing approaches are inappropriate and unhelpful in some social marketing situations. Over the years, a tension has existed in the social marketing scholarly community between those who believe that social marketing should follow a commercial marketing framework (Hastings and Saren 2003; Wood 2008) and those who believe a binding to commercial marketing models is not helpful (Peattie and Peattie 2003, 2011; Tapp and Spotswood 2013).

The development of social marketing theory has become fragmented (Singh and Dhir 2019). There are separate research streams in behavior change, downstream social marketing, upstream social marketing, and macro-social marketing (Hoek and Jones 2011; Kennedy 2016; Kennedy and Parsons 2012). The impetus for venturing beyond commercial marketing orthodoxy and developing a dedicated body of social marketing theoretical work is the limitations of commercial marketing effectiveness of contexts for which commercial marketing was not developed. That is, using commercial marketing concepts as the sole basis for social marketing limits the scope of social marketing programs to individual behavioral change and ignores the environmental context within which harmful behavior occurs (Wymer 2011).

The traditional emphasis of social marketers on behavioral change models has had limited success and is generally insufficient to produce sustained social change to address complex, wicked problems (French and Gordon 2019; Kennedy 2017). A stream of social marketing research has developed theoretical models that take a more comprehensive approach in order to enhance the potential for successful social marketing outcomes (Brennan et al. 2016). Hoek and Jones (2011) advocated combining upstream and downstream social marketing for more effective outcomes. Wymer (2011) developed a strategic social marketing model to guide a comprehensive and holistic approach to ameliorating social problems. Previte and Fry (2006) describe a harm chaining approach to identify upstream and downstream contributors to social problems and working collaboratively to reducing the social harm. Domegan et al. (2016) and Domegan et al. (2019) have developed a systems approach to the development of social marketing programs.

There are key differences in perspectives between these social marketing models. Wymer's approach (Wymer 2010; Wymer 2011; Wymer 2015) directs social marketers to identify the various causes of a social problem, weight those causes with respect to the degree to which each contributes to the social problem, weight the social marketer's ability to effect change for the causes, and then develop the most effective social 
marketing strategy and programs. The systems-thinking social marketing approach (Hastings and Domegan 2014) identifies stakeholders related to a social problem at the micro, meso, and macro levels, and then brings those stakeholders together in a collaborative relationship in which the stakeholders work together to ameliorate the social problem.

The systems-thinking approach views the social marketer as a team leader for a community of collaborating stakeholders. The emphasis is on increasing effectiveness by increasing cooperation among stakeholders of a social problem. The systemsthinking approach to social marketing is innovative. Its strength lies it its emphasis on the interactions among stakeholders of a social problem. Its weakness is in not accounting for the reticence of some stakeholders and the opposition of other stakeholders in ameliorating a social problem. It is difficult to imagine a win-win scenario for all stakeholders for all social problems.

Wymer's perspective viewed the social marketer as working independently, not collaboratively with stakeholders as recommended in the systems-thinking approach. The emphasis was on maximum effectiveness by targeting the strongest influences of a social problem which the social marketer could influence. Wymer's (2011) strategic social marketing model emphasizes maximum effectiveness in targeting the strongest contributors to a social problem. However, the Wymer model did not account for the interactions among the various stakeholders involved in influencing a social problem. The Wymer model did not envision the potential for greater effectiveness by collaborative work of a stakeholder coalition.

The purpose of this paper is to combine the strengths of the systems-thinking model and Wymer's (2011) model. The adapted model takes a holistic perspective in dealing with social problems for increased outcome effectiveness. An adaptive strategic social marketing model should allow for a myriad of social problems in varied contexts. In some cases, the focus should be on individual behavioral change. In other cases, the focus should be to work with stakeholder groups to promote positive change. In yet other cases, the focus should be on confrontation, not collaboration, to counter opposition to alleviating social problems. Sometimes, a combination of tactics may be best in achieving greatest effectiveness. The purpose of the adaptive model is to provide a means of developing practical and useful social marketing campaigns that can attain greater effectiveness in improving their target social problems (Levit and Cismaru 2020).

In the next section, we will provide a contextual background to provide an overview of the two major theoretical models for strategic social marketing. The advantages and disadvantages of each will be discussed as well as the need for a combinatory approach that maximizes the strengths of each model and minimizes each's weaknesses.

\section{Conceptual background}

Wymer (2011) presented a new model for strategic social marketing planning that integrated harm chaining, public health theory, and upstream and downstream social marketing. The motivation for the development of this model came from observing the emphasis of social marketing on developing campaigns that targeted individual behavior change. Few social marketing studies measured the outcome effectiveness of social 
marketing interventions. Those that did measure outcomes often reported minor or trivial improvements in the targeted social problem.

In diagnosing potential reasons for poorly performing social marketing campaigns, Wymer $(2010,2011,2015)$ found an overreliance on commercial marketing tactics like the 4 Ps and simple advertising campaigns that targeted individual consumers. In searching for alternative ways of thinking that might offer insights into improving social marketing effectiveness, Wymer was influenced by the economist Gardiner Means' (1962) emphasis on correctly identifying the causes of social problems if an effectiveness program for improving the social problem is to be found. Wymer was also influenced by prior research in public health (Wallack 1984), which understood that people's health and well-being is strongly influenced by the physical and socialeconomic environment. Other social marketing concepts also informed the development of Wymer's (2011) model, such as harm chaining (Polonsky et al. 2003; Previte and Fry 2006) and upstream social marketing (Andreasen 2006; Gordon 2011).

With an approach for identifying the major causes of social problems without respect to the nature or location of those causes, the ineffectiveness of social marketing programs in ameliorating wicked social problems like tobacco and alcohol consumption was obvious. For example, social marketers have periodically developed shortlived campaigns aimed at influencing individual behavioral change, when generations of tobacco industry (Kessler 2002) and alcohol industry (Mosher and Wallack 1981) marketing have created an environment which strongly supports the wicked social problems these industries cause.

Hence, Wymer (2010) argued that social marketers and social marketing researchers should begin to consider reducing the influence of major influences of social marketing problems, wherever they are found (in the environment or in the individual) rather than myopically focusing on individual behavior change or restricting their thinking to the confines of commercial marketing's simple $4 \mathrm{P}$ model. Advocating for change was insufficient to effect change without a better alternative. Thus, Wymer (2011) developed a social marketing strategic planning model to provide social marketers with a disciplined approach for identifying the major causes of a targeted social problem so that social marketing programs could be developed with greater effectiveness. The strength of Wymer's model is in identifying major influences of a social problem. The weakness of Wymer's model is that he viewed the social marketer as working independently and apart from other stakeholders who might have a positive contribution to make.

Domegan et al. (2020) and Hastings and Domegan (2018) developed another social marketing strategic model, also aimed at increasing the effectiveness of social marketing programs. Whereas Wymer's (2011) model sought to improve social marketing effectiveness by providing a structured approach for identifying the most influential causes of a social problem for ameliorative targeting, Domegan's model sought to improve social marketing effectiveness by promoting a multi-level stakeholder coalition.

Domegan et al. (2020) systems model promotes a collaboration among stakeholders as a means of gaining more cooperation in developing and implementing a social marketing problem that can achieve greater effectiveness in improving the target social problem. The strength of the systems model is that it brings together multiple stakeholders at different levels in the marketing system to form a coalition which could 
potentially have a greater impact on the social problem than if a lone social marketer worked independently without the collaboration of other stakeholders. The weakness of the systems model is that it assumes that a group of diverse stakeholders can be effectively led and managed in such a way that their diverse interests and perspectives will work collaboratively with synergy to substantively improve a wicked social problem.

While the Domegan et al. (2020) systems approach offers greater promise of effectiveness because it integrates implementation and multi-level cooperation into its conceptualization, the Wymer (2011) causative approach is beneficial because it helps to ensure that the emphasis of social marketers will be maintained on the stronger influences of a wicked social problem and not be diverted through a committee compromise or misunderstanding. Hence, the proposed adaptive model is presented here as a preferred means of combining the strengths of both social marketing strategic models.

This section presented a brief description of two strategic social marketing models. The combinatory adaptive model is presented next and more facets of each model will be explained further.

\section{Adaptive social marketing model}

The first part of the model is aimed at identifying the causes of a target social problem and then assessing the relative influence of each cause on the social problem. The foundation for this part of the model is based on Wymer's $(2011,2015)$ work, which emphasized identifying and prioritizing causes of a social problem for subsequent targeting and ameliorating.

The second part of the model is aimed at identifying relevant stakeholders and determining the degree to which each can be recruited to work collaboratively toward ameliorating the social problem. The third part of the model is aimed at developing the most effective plan for ameliorating the social problem. These parts of the model are based on the work of Domegan et al. (2016, 2019, 2020), which emphasized the development of a stakeholder coalition in implementing social marketing programs. The model's steps are described next.

\subsection{Step 1: Define social problem}

Social marketers should be clear with respect to the nature of the targeted social problem (Wymer 2011). A lack of consensus about the nature of the social problem will lead to problems in identifying social marketing objectives and potential solutions. For example, is the problem alcohol consumption, underage drinking, binge drinking, alcohol addiction, or alcohol-impaired driving?

If the social problem is not accurately understood and defined, then proposed solutions to improving the social problem will be less effective than had the problem been precisely defined (Means 1962). Using the alcohol consumption example again, is the perceived social problem binge drinking at universities, alcohol-impaired driving, underage drinking, or an increasing rate of alcoholism in the general population? A precise social problem description is essential because, without it, the major causes of 
the social problem cannot be accurately identified (the purpose of the next step in the model) for targeting.

\subsection{Step 2: Perform a causal analysis}

The purpose of performing a causal analysis is to identify the substantive causes or influencers of the defined social problem. Once the major causes of a social problem are identified, social marketers can develop programs to ameliorate them. This may sound like an obvious step. However, the lack of effectively targeting the major causes of social problems has led to relatively ineffective social marketing campaigns. For example, social marketers have developed anti-obesity campaigns that informed people to eat more fruits and vegetables. These campaigns have proved to be ineffective in reducing obesity, probably because the campaigns ignored major causes of obesity like enduring and intensive industry advertising, grocery store merchandizing, and changing social conditions in society and in certain communities (Chopra and Darnton-Hill 2004; Kessler 2010; Nestle 2013).

A systems approach considers both individual factors as well as the environmental context in which the social problem occurs. Hence, potential causes of a social problem are not overlooked by a myopic emphasis on individual behavior change. Figure 1 depicts the individual and environmental influencers of a social problem (adapted from Wymer 2011).

As previously discussed, an effective social marketing program cannot be developed without a clear definition of the social problem and an accurate understanding of its causes. With respect to identifying the contributors of a social problem, a systematic

\section{Causal Analysis}

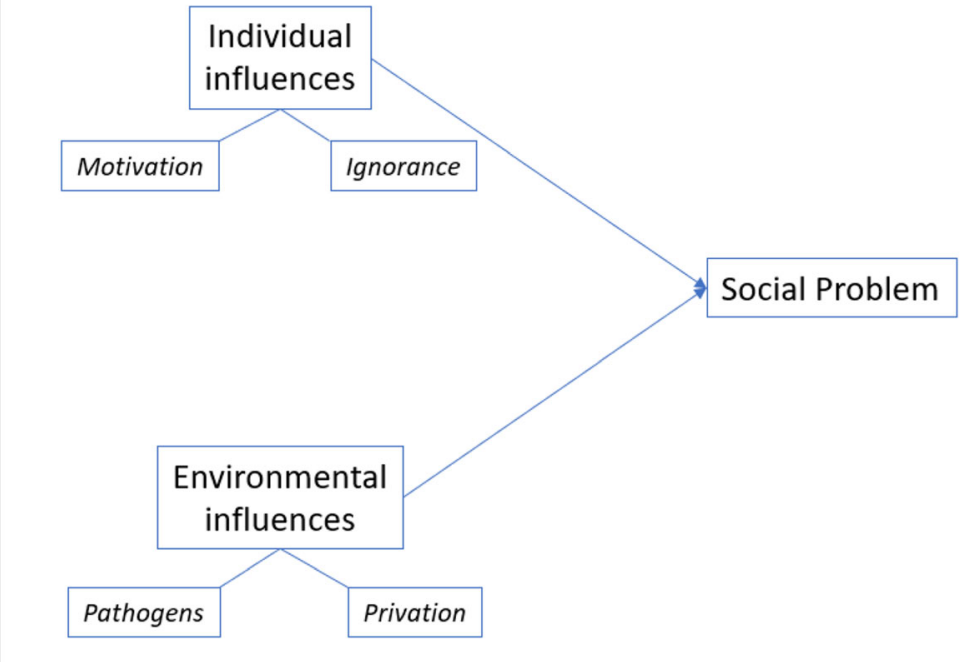

Fig. 1 Casual analysis 
and holistic analysis is needed. Not only is it important to identify the causes of a social problem, it is important to understand the degree to which each identified cause contributes to the target social problem.

A major benefit of not constraining social marketing strategy to a commercial marketing paradigm is that social marketers should perceive people as individuals, not consumers, and the social problem as an interaction between individuals and their environment, not as a consumption behavior. Hence, the causal analysis takes a bottom-up approach, beginning by identifying environmental contributors to the target social problem.

A holistic approach is taken with respect to the environment (see Fig. 2). The environmental context can be separated into three levels: micro, meso, and macro. The micro-environment refers to the context in which a person lives. The microenvironment includes an individual's home environment, family life, lifestyle, routines and habits, and so forth. The meso-environment occurs not at the home level, but at the community level. The meso-environment includes an individual's community such as work, school, neighborhood, city, and so forth. The macro-environment occurs at the society level. The macro-environment includes an individual's society, culture, public policy, and so forth. The search for environmental contributors or causes of a social problem should include all environmental levels (Brennan et al. 2016; Gordon et al. 2018).

In the next section, we will discuss the causal analysis model (see Fig. 1) because the model is used in step 2 to identify and prioritize the causes of the social program that was defined in step 1 . We will begin by discussing environmental influences (privation or pathogens) on the social problem. Potential environmental influences or causes of

\section{Environmental context}

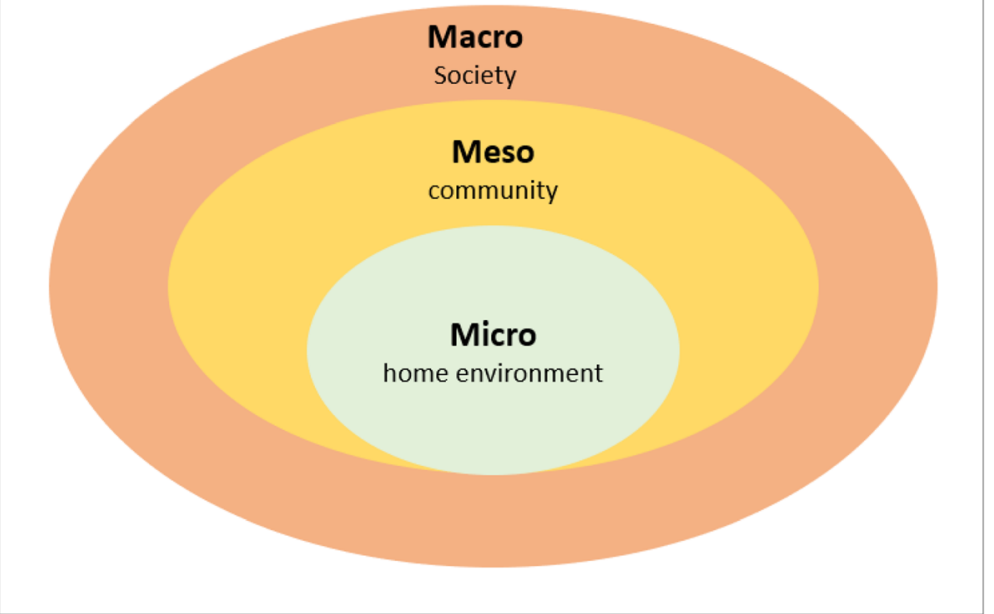

Fig. 2 Environmental context 
the social problem may exist at the micro, meso, or macro levels. Then, we discuss individual influences (ignorance or motivation) on the social problem.

\subsubsection{Privation}

In utilizing the model in Fig. 1 to identify influence on the social problem, we begin with environmental influences. We will begin with privation, and then discuss pathogens.

Privation refers to resources that are not available to a group of individuals; resources that are needed to achieve a healthful state or condition (Wymer 2011). These resources could be water, food, clothing, shelter, or other supports needed for healthy living. Causes of privation are more likely to exist at the meso and macro environmental levels than at the micro environmental level.

For example, in some regions of rural America, the lack of waste sanitation due to structural poverty creates a social problem. The lack of a wastewater infrastructure results in human diseases like hookworm that were thought to have been eradicated in advanced countries with the advent of indoor plumbing (Flowers 2020). The lack of wastewater sanitation presents a problem at the individual/micro and community/meso levels, but is caused by a lack of funding from the state and federal governments (society/macro level).

The absence of a wastewater sanitation infrastructure in parts of rural America represents a type of privation. The lack of a sanitation system causes the resultant social problems. Sometimes, however, the social problem is caused by something in the environment (social or biophysical) that creates a social problem-pathogens.

\subsubsection{Pathogens}

The next categories of potential influences on a social problem are pathogenic agents or pathogens (see Fig. 1). Pathogens refer to unhealthy substances or conditions that are present in the environment that cause an unhealthy state (Wymer 2011). Pathogens can be present in the physical environment, such as toxins in the soil, air, water, or consumer products. Pathogens can be present in the social-political environment, such as some types of marketing activities, unhealthy social norms, or public policies that fail to promote and protect the general welfare of the citizenry (Jenkins 2003).

An example of a pathogen at the micro level could be radon gas that leaks into someone's home from cracks in floors or walls, construction joints, or gaps around service pipes. The presence of radon in the air of someone's home may cause lung cancer. Radon is the second leading cause of lung cancer, after cigarette smoking (CDC 2020).

As an example of a pathogen at the meso/community level, the American community of Parkersburg, West Virginia, was exposed to a cancer-causing chemical from a Dupont Chemical Company factory for decades. The chemical, called perfluorooctanoic acid, or PFOA, was used in the manufacturing of a Dupont plastic nonstick coating called Teflon. PFOA leaked into the community's water from Dupont's landfill waste disposal site. It was ultimately discovered that the corporation knew about the potential harm of PFOA for decades (Bilott 2019; Soechtig and Seifert 2018). 
And, as an example of a pathogen at the macro/society level, phthalates are a class of chemicals that are used to soften plastics, bind fragrances in products, and act as solvents and fixatives. Baby bottles, teething rings, and toys are (or used to be) made with phthalates or bisphenol A (BPA). These chemicals, in the body, suppress or mimic hormones and disrupt normal development and growth (Children's Environmental Health Network 2010). The presence of these pathogens from the US chemical industry has exposed a good portion of the American population to a greater risk of attentiondeficit hyperactivity disorder, breast cancer, obesity, type II diabetes, low IQ, neurodevelopmental issues, behavioral issues, autism spectrum disorders, altered reproductive development, and male fertility issues (Westervelt 2015).

Some pathogens have the capability of causing wicked social problems and have the potential of causing great harm. Consequently, Wymer $(2010,2011)$ was motivated to pursue alternatives to traditional behavioral modification social marketing campaigns, targeting individuals, in order to increase the outcomes of social marketing programs.

Some influences on social problems are linked to individuals, however. Hence, Wymer's (2011) model (see Fig. 1) includes two classes of individual-level variables: ignorance and motivation. We will discuss these next.

\subsubsection{Ignorance}

In some instances, individuals may not know or understand something that would lead them to make more healthful decisions. Individuals may be unaware of how to avoid or prevent an unhealthy state.

During the 2020 corona virus pandemic, social marketing campaigns were instrumental in informing people to avoid spreading COVID-19 by wearing masks, avoiding social gatherings, practicing social distancing, and regular hand washing (Lee 2020; NCDHHS 2020).

A much more difficult issue in dealing with ignorance during the 2020 corona virus pandemic is the widespread propagation of disinformation by ultra-right-wing political sources (Lawson 2020). Ultra-right-wing disinformation sources and their audiences share a distrust of public institutions. Disinformation memes have claimed that the corona virus was not real or was only as severe as the common flu, and have claimed that wearing masks and practicing social distancing is unnecessary and is done by the government to restrict individual freedom. Hence, conspiracy theories and false information abound on these sites (Lynas 2020; Mello 2020; Timberg 2020). As a result of these disinformation campaigns, a portion of the population is resistant to valid public health information and programs. There are concerns that the ultra-right's conspiracy theories will encourage some to avoid getting the vaccine, resulting in the prolonging of the pandemic (Brito 2020; Brown 2020; Pierre 2020).

Ignorance can manifest in an absence of knowledge on a topic or in the belief in false information. An absence of knowledge can be corrected by an effective social marketing campaign. However, when individuals believe false information, they may not believe facts and information that are incongruent with their false beliefs. These individuals may lack the motivation to attend to or process valid information. Motivation issues represent our next category of individual-level influences of social problems (see Fig. 1), which we will discuss next. 


\subsubsection{Motivation}

Individuals may lack a desire or willingness to make beneficial changes. The short-term benefits of an unhealthy behavior may have a greater influence than the long-term benefits of changing the behavior. Individuals may feel that they are unable to change an unhealthy condition (Wymer et al. 2006).

Several behavioral change theories have been used by social marketers to understand and respond to motivation issues of individuals (Helmig and Thaler 2010). The most prominent behavior change theory used by social marketers has been the Theory of Reasoned Action. Other theories that have been used include Social or Observational Learning Theory, Social Cognitive Theory, the Health Belief Model, and the Cost Benefit Model (Helmig and Thaler 2010; Wymer et al. 2006).

\subsection{Step 3: Prioritize causal influences on the social problem}

After the causes of the social problem have been identified in step 2, it is important to determine the degree to which each contributes to the social problem. By identifying the most influential causes of a social problem, social marketers can devote their time and resources toward lessoning the influence of the greatest contributors (Wymer 2011). A weighting scheme that assigns some level of proportionality to each cause is more useful for planning than a simple ranking of causes (Wymer 2015).

When stakeholders are recruited to collaborate in ameliorating the social problem, the prioritization of causes may change. Next, we will discuss stakeholder collaboration.

\subsection{Step 4: Identify stakeholders}

There is a system of interactive stakeholders involved in or interested in dealing with social problems. The system includes all relevant actors, their actions and interactions (Brennan et al. 2016; Domegan et al. 2016; Domegan et al. 2020). Every actor that has an interest or involvement in the social problem can be considered a stakeholder, including policy makers, consumers, regulators, local authorities, industry, and civil society groups (Domegan et al. 2019). Brennan et al. (2016) provide a case study which describes the identification of stakeholders.

Stakeholders will be classified in a simple categorization scheme. Social marketers want to ameliorate a social problem that currently exists. Hence, they want to change the status quo, or the existing situation, to a more healthful condition. Borrowing from Layton's (2015) categories, social marketers are challengers who seek change. Challengers are stakeholders who seek to change the conditions that created and maintain the social problem. Resisters are stakeholders who want to maintain the status quo. They benefit from the status quo or they believe in the virtuousness of the status quo and will resist change. Doers are the stakeholders who are engaged in the targeted unhealthy behaviors or who are otherwise harmed or personally affected by the social problem (Domegan et al. 2020). 


\subsubsection{Understanding stakeholder perspectives}

Stakeholders will have different perspectives. They may perceive the causal influences of the social problem differently. Different stakeholders may have different interests and incentives with respect to ameliorating the social problem. Stakeholders' perceptions may be influenced by the environmental level (micro, meso, or macro) in which they operate (Domegan et al. 2019). It is important to communicate with stakeholders in order to understand their perspectives and perceptions, as well as to determine the assistance each can provide in a collective response in dealing with the social problem (Lindenberg and Crosby 1981; Varvasovszky and Brugha 2000).

With respect to the stakeholder group called doers, understanding their values, motivations, social networks, and communities will lead to insights and enhanced understanding of the social problem and the system dynamics that interact with the individuals most affected by the social problem (Petty et al. 2009).

With respect to the stakeholder group called challengers, they may have different perceptions of the nature of the social problem, its causality, and pathways toward its alleviation (Selsky 1991). Challengers may exist at different environmental levels and interact with different sets of stakeholders. Challengers may view acceptable ways of changes needed to correct the social problem differently (Domegan et al. 2019).

With respect to the stakeholder group called resisters, they may have different incentives that motivate them to maintain the status quo. They may believe that change will oppose their self-interests. Some resisters may staunchly oppose any attempts at system change, whereas others may only object to certain types of changes (Carr et al. 2009; Del Val and Fuentes 2003; Lozano 2013).

Once social marketers have developed a rich understanding of system stakeholder perspectives, they should carefully consider the creation of a stakeholder coalition that can work collectively and effectively in making a meaningful improvement on the social problem. Attempting to include all stakeholders in a collective, cooperative team would likely produce undesirable outcomes. Some resisters, if included, would have incentives to sabotage the efforts of challengers. Some challengers may be so committed to only one pathway for change that compromise and consensus would be unthinkable. Hence, social marketers should cultivate those stakeholders who can help further the social marketing efforts rather than hinder them.

\subsubsection{Form stakeholder coalition}

Social marketers should form a coalition of stakeholders that can make a positive contribution to ameliorating the social problem. The coalition is a collective of stakeholders that unite and engage in social problem-solving for the purpose of ameliorating a social problem (Waddock 1989). The composition of the stakeholder coalition should be carefully considered. Understanding stakeholder perspectives prior to forming a coalition allows social marketers to identify resisters who might sabotage the coalition's work or other potentially uncooperative stakeholders. It may not be useful to include in the coalition stakeholders who are unlikely to work collaboratively with others.

The stakeholder coalition will need to be managed effectively to attain successful outcomes. Three factors are essential: (1) the extent to which stakeholders are 
committed to shared goals, (2) the quality of communication and power-sharing among stakeholders, and (3) the degree of trust among coalition members and the quality of its leadership (Aas et al. 2005; Savage et al. 2010).

\subsection{Step 5: Establish objectives}

The stakeholder coalition should develop effective communication networks and shared problem-solving processes. Stakeholders may need to compromise, to be open to other stakeholder perspectives, and to be flexible in dealing with challenges (Domegan et al. 2020; Layton 2015). Although a rigid course of action may not be advisable, stakeholders should arrive at a consensus on their primary goals (Innes 2004). The degree of desired improvement of the targeted social problem should be explicit. A properly stated goal will have these characteristics: (1) the variable that is to be changed should be identified, (2) the degree to which the variable is to be changed should be stated, and (3) the deadline to attain the desired change is explicit (Power 2015; Wallis 2006).

\subsection{Step 6: Develop plans for reducing influence of causes of social problem}

The coalition of stakeholders will have to be carefully managed for the group to work effectively. Most problems will arise from value differences among stakeholders. Coalition members with different values from the majority should feel free to express themselves. Stakeholders may be able to work toward the objective of ameliorating the social problem through different pathways. A variety of tactics from the various stakeholders is welcome if they further the primary objectives related to improving the target social problem (Spicer 2007; Weible 2007).

In identifying the causes of a target social problem, especially complex or wicked social problems, there are often multiple causes present at different environmental levels (micro, meso, and macro). The stakeholder coalition may create separate subgoals and separate plans to reduce the influence of different causes. Since stakeholders may operate at different environmental levels, they may develop and implement separate plans to deal with causes of the social problem present in their operational realm. Having divergent plans under implementation at different environmental levels by different stakeholders gives stakeholders greater voice in the coalition and leads to their more intensive engagement. Hence, the coalition can deal with a complex social problem in a comprehensive manner.

\subsection{Step 7: Implement plans}

For a complex social problem, the stakeholder coalition may develop several plans targeting multiple causes of the social problem existing at different environmental levels. Coalition members can determine which stakeholders will implement each plan and develop target deadlines and so forth. Stakeholders should communicate with each other so the coalition will understand how a comprehensive program of integrated plans is progressing.

Each discrete plan will have its own subordinate goals and the comprehensive program of plans will have an overall objective reflecting the desired level of correction 
of the social problem. Periodic evaluation of the implemented plans is useful to determine how the plan is progressing and to identify areas needing adjustment.

\section{Implications for theory and practice}

The adaptive social marketing strategic model presented has substantial implications for theory and practice. With respect to implications for theory, the adaptive social marketing model integrates multiple theoretical viewpoints into a multidisciplinary approach in order to arm the social marketer with a means of program development to ameliorate a range of social problems, from the simple to the complex.

Ideas from a variety of perspectives are integrated into the adapted social marketing model presented in this paper for the purpose of developing a comprehensive theoretical and practical model to guide future development of social marketing. Perspectives from traditional social marketing, economics, public health, systems thinking, stakeholder analysis and management, and market systems are used.

With respect to future research on the theoretical foundations of the adaptive social marketing model, each facet of the model could benefit from further research. Should the role of the social marketer be a leadership role or a moderator role for the stakeholder coalition? What leadership style is most effective in managing a stakeholder coalition? How should the weighting of causes of a social problem be accomplished and what considerations should be given to adapting causal weights based on the probability of successful amelioration?

Further theoretical development of the adaptive social marketing model should include forming and managing a stakeholder coalition. How do we best achieve a meaningful improvement from a diverse group of stakeholders with differing perspectives, capabilities, and resources? In some instances, compromise among stakeholders is needed. How can a coalition best influence public policy, develop a social movement, or change individual behaviors; depending on the goals and objectives of the coalition? Future research on all these areas is needed to further develop the adaptive social marketing model.

With respect to the model's implications for practice, social marketers can use the model as a process guide to develop more effective social marketing programs. Rather than addressing a social problem with a simple commercial marketing $4 \mathrm{P}$ framework, social marketers are enabled to form a productive coalition of stakeholders, targeting the major causes of a social problem, and develop and implement a program for making the social problem better. The emphasis will be on increasing social marketing effectiveness to improve people's lives and improve the well-being of society.

\section{Conclusion}

Social marketers have been adjusting their approaches for improving social problems over time in order to improve their effectiveness. Formerly, problems were generally treated with behavioral change solutions targeting individuals. There is a growing consensus that complex societal problems require a more holistic, systems-thinking approach (Domegan et al. 2016). The process described in this paper views the social 
marketer's role as a prime mover and manager of a collective stakeholder response aimed at ameliorating a target social problem.

Identifying the cross-environmental causes of a social problem and their relative influence on the social problem facilitates the identification of interested stakeholders. Encouraging a collective response in alleviating a social problem from a coalition of stakeholders is a challenging but potentially effective means of generating a complex, multi-level series of actions to mitigate causes to a social problem. Stakeholders may have different perspectives, values, and incentives. It may be impractical and selfdefeating to attempt a coalition of all stakeholders. Some stakeholders may be intractable. Other stakeholders may be invested in maintaining the status quo and might work against the coalition's progress. Hence, the coalition would be best served by stakeholders who can agree on overall goals in dealing with a social problem.

While the coalition should agree on its primary objectives, it is unlikely to agree upon a single, predetermined plan of action. It may be most effective to encourage stakeholders operating at different environmental levels to develop sub-goals and tactical plans they can implement and that will help the coalition attain its overall primary objectives.

\section{References}

Aas, C., Ladkin, A., \& Fletcher, J. (2005). Stakeholder collaboration and heritage management. Annals of Tourism Research, 32(1), 28-48.

Andreasen, A. R. (Ed.). (2006). Social marketing in the 21st century. Thousand Oaks, California: Sage Publications.

Bilott, R. (2019). Exposure: poisoned water, corporate greed, and one lawyer's twenty-year battle against Dupont. Atria Books: New York City.

Bloom, P. N., \& Novelli, W. D. (1981). Problems and challenges in social marketing. Journal of Marketing, 45(2), 79-88.

Brennan, L., Previte, J., \& Fry, M. L. (2016). Social marketing's consumer myopia. Journal of Social Marketing, 6(4), 219-239.

Brito, C. (2020). Facebook will remove misinformation about COVID-19 vaccines. CBS News. Accessed online on 7-Dec-2020 at https:/www.cbsnews.com/news/facebook-covid-19-vaccines-misinformation/.

Brown, R. (2020). Facebook to remove misinformation about Covid vaccines. Accessed online on 7-Dec2020 at https://www.cnbc.com/2020/12/03/facebook-to-remove-misinformation-about-coronavirusvaccines.html.

Carr, D., Howells, A., Chang, M., Hirji, N., \& English, A. (2009). An integrated approach to stakeholder engagement. Healthcare Quarterly, 12, 62-70.

CDC. (2020). Radon in the home. Accessed online at https://www.cdc.gov/nceh/radiation/brochure/profile radon.htm on 6-December-2020.

Children's Environmental Health Network. (2010). Plastics \& plastic toys. Accessed 6-December-2020 at https://health.ucdavis.edu/mindinstitute/resources/resources_pdf/Plastics_and_Plastic_Toys_7_14.pdf.

Chopra, M., \& Darnton-Hill, I. (2004). Tobacco and obesity epidemics: not so different after all? British Medial Journal, 328(7455), 1558-1560.

Del Val, M. P., \& Fuentes, C. M. (2003). Resistance to change: a literature review and empirical study. Management decision.

Domegan, C., Brychkov, D., McHugh, P., McNamara, Á., Harkin, K., Fitzgerald, C., \& O’Donovan, D. (2020). Marketing systems: a listen, learn, leverage framework. Journal of Macromarketing, Online first edition, 1-16. Available at https://doi.org/10.1177/0276146720922282.

Domegan, C., McHugh, P., Devaney, M., Duane, S., Hogan, M., Broome, B., Layton, R., Joyce, J., Mazzonetto, M., \& Piwowarczyk, J. (2016). Systems-thinking social marketing: conceptual extensions and empirical investigations. Journal of Marketing Management, 32(11-12), 1123-1144. 
Domegan, C., McHugh, P., Flaherty, T., \& Duane, S. (2019). A dynamic stakeholders' framework in a marketing systems setting. Journal of Macromarketing, 39(2), 136-150.

Flowers, C. (2020). Waste: one woman's fight against America's dirty secret. The New Press: New York City.

French, J., \& Gordon, R. (2019). Strategic social marketing: for behaviour and social change. Thousand Oaks, California: Sage Publications.

Gordon, R. (2011). Critical social marketing: definition, application and domain. Journal of Social Marketing, l(2), 82-99.

Gordon, R., Butler, K., Cooper, P., Waitt, G., \& Magee, C. (2018). Look before you LIEEP. Journal of Social Marketing, 8(1), 99-119.

Hastings, G., \& Domegan, C. (2014). Social marketing: from tunes to symphonies (2nd ed.). Abingdon: Routledge.

Hastings, G., \& Domegan, C. (2018). Social marketing: rebels with a cause. Abingdon: Routledge.

Hastings, G., \& Saren, M. (2003). The critical contribution of social marketing: theory and application. Marketing Theory, 3(3), 305-322.

Helmig, B., \& Thaler, J. (2010). On the effectiveness of social marketing - what do we really know? Journal of Nonprofit \& Public Sector Marketing, 22(4), 264-287.

Hoek, J., \& Jones, S. C. (2011). Regulation, public health and social marketing: a behaviour change trinity. Journal of Social Marketing, 1(1), 32-44.

Innes, J. E. (2004). Consensus building: clarifications for the critics. Planning theory, 3(1), 5-20.

Jenkins, C. D. (2003). Building better health: a handbook of behavioral change. Washington D.C.: Pan American Health Org.

Kennedy, A. M. (2016). Macro-social marketing. Journal of Macromarketing, 36(3), 354-365.

Kennedy, A. M. (2017). Macro-social marketing research: philosophy, methodology and methods. Journal of Macromarketing, 37(4), 347-355.

Kennedy, A. M., \& Parsons, A. (2012). Macro-social marketing and social engineering: a systems approach. Journal of Social Marketing, 2(1), 37-51.

Kessler, D. (2002). A question of intent: a great American battle with a deadly industry. New York City: Public Affairs.

Kessler, D. (2010). The end of overeating: taking control of the insatiable American appetite. Rodale.

Kotler, P., \& Zaltman, G. (1971). Social marketing: an approach to planned social change. Journal of Marketing, 35(3), 3-12.

Lawson, S. (2020). Right-wing responsible for pushing coronavirus disinformation on Twitter worldwide, new report says. Cybersecurity. Accessed online on 7-Dec-2020 at https://www.forbes.com/sites/ seanlawson/2020/04/21/right-wing-responsible-for-pushing-coronavirus-disinformation-on-twitterworldwide-new-report-says/?sh=7640ab4597ff.

Layton, R. (2015). Formation, growth and adaptive change in marketing systems. Journal of Macromarketing, $35(3), 302-319$.

Lee, N. (2020). Reducing the spread of COVID-19: a social marketing perspective. Accessed on 7-Dec-2020 online at https://isocialmarketing.org/isma-news-desk/reducing-the-spread-of-covid-19-a-social-marketing-perspective.

Levit, T., \& Cismaru, M. (2020). Marketing social marketing theory to practitioners. International Review on Public and Nonprofit Marketing, 17, 237-252.

Lindenberg, M., \& Crosby, B. (1981). Managing development: the political dimension. Hartford: Kumarian Press.

Lozano, R. (2013). Are companies planning their organisational changes for corporate sustainability? An analysis of three case studies on resistance to change and their strategies to overcome it. Corporate Social Responsibility and Environmental Management, 20(5), 275-295.

Lynas, M. (2020). COVID: Top 10 current conspiracy theories. Cornell Alliance for Science, accessed online on 7Dec-2020 at https://allianceforscience.cornell.edu/blog/2020/04/covid-top-10-current-conspiracy-theories/.

Means, G. C. (1962). The corporate revolution in America. New York City: Crowell-Collier Press.

Mello, J. (2020). Far-right spreads COVID-19 disinformation epidemic online. Technewsworld, accessed 7Dec-2020 online at https://www.technewsworld.com/story/86648.html.

Mosher, J. F., \& Wallack, L. M. (1981). Government regulation of alcohol advertising: protecting industry profits versus promoting the public health. Journal of public health policy, 2(4), 333-353.

NCDHHS. (2020). NCDHHS launches new social media campaign as part of larger effort to slow the spread of COVID-19. Accessed online on 7-Dec-2020 at https:/www.ncdhhs.gov/news/press-releases/ncdhhslaunches-new-social-media-campaign-part-larger-effort-slow-spread-covid.

Nestle, M. (2013). Food politics: how the food industry influences nutrition and health (Vol. 3). Univ of California Press: Berkeley, California.

Peattie, K., \& Peattie, S. (2011). The social marketing mix - a critical review. In G. Hastings, K. Angus, \& C. Bryant (Eds.), The sage handbook of social marketing (pp. 152-166). London: Sage Publications. 
Peattie, S., \& Peattie, K. (2003). Ready to fly solo? Reducing social marketing's dependence on commercial marketing theory. Marketing theory, 3(3), 365-385.

Petty, R., Barden, J., \& Wheeler, S. (2009). The elaboration likelihood model of persuasion: developing health promotions for sustained behavioral change. In R. DiClemente, R. Crosby, \& M. Kegler (Eds.), Emerging theories in health promotion practice and research (2nd ed.). San Francisco: Jossey-Bass.

Pierre, J. (2020). Anti-vaccine and COVID-19 conspiracy theories: a perfect storm. Psychology Today. Accessed online on 7-Dec-2020 at https:/www.psychologytoday.com/us/blog/psych-unseen/202005/ anti-vaccine-and-covid-19-conspiracy-theories-perfect-storm.

Polonsky, M. J., Carlson, L., \& Fry, M. L. (2003). The harm chain: a public policy development and stakeholder perspective. Marketing Theory, 3(3), 345-364.

Power, D. (2015). What are the characteristics of a good goal statement? Planning skills, accessed online on 812-2020 at http://www.planningskills.com/askdan/16.php.

Previte, J., \& Fry, M. L. (2006). Conceptualising the harm chain in social marketing strategy: a drink drive application. In Australian and New Zealand Marketing Academy conference (ANZMAC) (p. 8).

Savage, G. T., Bunn, M. D., Gray, B., Xiao, Q., Wang, S., Wilson, E. J., \& Williams, E. S. (2010). Stakeholder collaboration: implications for stakeholder theory and practice. Journal of Business Ethics, 96(1), 21-26.

Selsky, J. W. (1991). Lessons in community development: an activist approach to stimulating interorganizational collaboration. The Journal of Applied Behavioral Science, 27(1), 91-115.

Singh, S., \& Dhir, S. (2019). Structured review using TCCM and bibliometric analysis of international causerelated marketing, social marketing, and innovation of the firm. International Review on Public and Nonprofit Marketing, 16, 335-347.

Soechtig, S., \& Seifert, J. (2018). The devil we know: the chemistry of a cover-up [DVD]. California: Atlas Films.

Spicer, C. H. (2007). Collaborative advocacy and the creation of trust: toward an understanding of stakeholder claims and risks. In E. L. Toth (Ed.), The future of excellence in public relations and communication management (pp. 27-40). Mahwah: Sage.

Tapp, A., \& Spotswood, F. (2013). From the 4Ps to COM-SM: reconfiguring the social marketing mix. Journal of Social Marketing, 3(3), 206-222.

Timberg, C. (2020). Covid disinformation sites often use tools from Google, Facebook and Apple, report finds. The Washington Post, accessed 7-Dec-2020 at https:/www.washingtonpost.com/technology/2020/12/04/covidscam-disinformation/.

Varvasovszky, Z., \& Brugha, R. (2000). A stakeholder analysis. Health policy and planning, 15(3), 338-345.

Waddock, S. A. (1989). Understanding social partnerships: an evolutionary model of partnership organizations. Administration \& Society, 21(1), 78-100.

Wallack, L. (1984). Social marketing as prevention: uncovering some critical assumptions. Advances in Consumer Research, 11(1), 682-687.

Wallis, A. M. (2006). Sustainability indicators: is there consensus among stakeholders? International journal of environment and sustainable development, 5(3), 287-296.

Weible, C. M. (2007). An advocacy coalition framework approach to stakeholder analysis: understanding the political context of California marine protected area policy. Journal of Public Administration Research and Theory, 17(1), 95-117.

Westervelt, A. (2015). Phthalates are everywhere, and the health risks are worrying. How bad are they really? The Guardian. Accessed 6-December-2020 at https://www.theguardian.com/lifeandstyle/2015/feb/10/ phthalates-plastics-chemicals-research-analysis.

Wood, M. (2008). Applying commercial marketing theory to social marketing: a tale of 4Ps (and a B). Social Marketing Quarterly, 14(1), 76-85.

Wymer, W. (2010). Rethinking the boundaries of social marketing: activism or advertising? Journal of Business Research, 63(2), 99-103.

Wymer, W. (2011). Developing more effective social marketing strategies. Journal of Social Marketing, 1(1), 17-31.

Wymer, W. (2015). Chapter 1: formulating effective social marketing and public health communication strategies. In W. Wymer (Ed.), Innovations in social marketing and public health communication: improving the quality of life for individuals and communities, pp. 3-32. Springer: New York City.

Wymer, W., Knowles, P., \& Gomes, R. (2006). Nonprofit marketing: marketing management for charitable and nongovernmental organizations. Thousand Oaks: Sage.

Publisher's note Springer Nature remains neutral with regard to jurisdictional claims in published maps and institutional affiliations. 